\title{
Beliefs and Knowledge about Parkinson's Disease
}

\author{
Susan Moore (smoore@swin.edu.au) \\ Simon Knowles (sknowles@swin.edu.au) \\ Faculty of Life and Social Sciences \\ Swinburne University of Technology, Hawthorn VIC 3122 Australia
}

\begin{abstract}
A survey of public attitudes showed that there is significant stigma perceived to be associated with Parkinson's disease (PD), as well as significant misconceptions about the course and outcomes of the disease. Negative attitudes to PD were associated with perceived stigma, (younger) age, knowledge of a sufferer and knowledge of the disease. Perceived stigma, negative attitudes and incorrect beliefs are likely to impinge on the psychosocial well-being of those living with the disease, particularly those with early onset. The data from this study was collected from 200 householders and suggest that more public information about positive lifestyle possibilities for those living with Parkinson's would be of value to disease sufferers and their carers.
\end{abstract}

Keywords: Parkinson's Disease; Health Outcomes; Attitudes; Stigma

\section{Introduction}

Parkinson's disease (PD) is a progressive degenerative neurological disorder characterised by tremors, slow movements, stiffness in arms and legs and balance problems (Anderson, Anderson, \& Glanze. 1998). Next to Alzheimer's Disease it is the most common neurological disorder in Australia, estimates suggesting there are currently over 80,000 cases in this country with 4000 new diagnoses each year (Parkinson's Victoria Inc., 2005). PD is predominantly diagnosed in individuals over 50, however it is not unknown in younger cohorts, with up to $30 \%$ of Parkinson's sufferers diagnosed before the age of 50 (Parkinson's Victoria Inc., 2005). As the population of Australia ages, the prevalence of this disease is likely to increase.

Several studies have shown that individuals with PD report a variety of symptoms that are adversely associated with their quality of life. These include psychological distress and depression, cognitive impairment, physical mobility problems, social isolation, emotional reactions, sexual problems and dysfunction, sleeping problems and fatigue (e.g., Schrag, Jahanshahi, \& Quinn, 2001; Schreurs, De Ridder, \& Bensing, 2000). Some of these symptoms are directly related to the disease course, but some may be a consequence of negative reactions to symptoms, by the sufferer or by the community at large. For example, one of the most adverse effects of living with PD is reported to be its impact on an individual's social interactions (Schrag et al., 2000; Shreurs et al., 2000). This may relate to common symptoms of Parkinson's such as masked facial expressions and speech problems, which make it harder for others to communicate and leave open the way for social misunderstanding (Lyons \& Tickle-Degnen, 2003; Simons, Pasqualini, Reddy, \& Wood, 2004). It could also relate to those with PD being more likely to withdraw from social contact because of embarrassment, perceived communication difficulties or other issues relating to their illness. Because of such problems, individuals living with PD may have a reduced social support network making them more susceptible to depression and reduced quality of life.

While the effects relating to PD differ from person to person, over time the symptoms and severity of the disease become increasingly debilitating (Abudi, BarTal, Ziv, \& Fish, 1997). However, this process can take many years, so those with PD may enjoy significant periods of time before symptoms become debilitating, especially if treatment regimes are initiated early. Thus, enhancement of quality of life, and the maintenance of positive mood, social contacts and work/leisure interests are particularly important.

The focus of this study is on public attitudes to Parkinson's disease. Public attitudes to disease are important, because they shape the context in which the ill person and their families and carers must live. When diseases are negatively viewed by the public, there may be less sympathy or support available for the sufferers and their families, sufferers may be stigmatised, and attitudes may even influence the level of funding available for medical research (Keusch, Wilentz, \& Kleinman, 2006). Public sympathy for some diseases and not others appears to relate to a range of factors, including age of the 'typical' sufferer, mode of transmission, and physical and cognitive symptomatology. For example children's and young person's diseases receive more public sympathy and relatively more research dollars than diseases characteristic of older persons (Clarke, 2005). Those suffering from so-called life style diseases, for example those related to smoking and obesity, may be viewed as responsible for their condition and therefore receive less sympathy than those with illnesses for which causes are unknown or apparently unrelated to life style (Keusch et al., 2006; Mateu-Gelabert, Maslow, \& Flom, 2005). Sexually transmissible diseases are often considered particularly blameworthy and 'dirty' (Moore \& Rosenthal, 1996; Reidpath, Brijnath, \& Chan, 2005; Rosenthal \& Moore, 1994). Conditions that lead to physical or cognitive disabilities which the public may consider unattractive, frightening, or related to mental retardation or mental illness, are often stigmatised (Hills \& MacKenzie, 2002; Jenetette, Funk, \& Murdaugh, 2005). 
Disease stigma can be overt, as in the case of shunning of lepers, or in more modern times, the fear and denial associated with HIV/AIDS, particularly in Africa but relatively recently also in the western world. More subtle are the negative attitudes associated with some diseases which, while they are 'accepted' in enlightened societies, are somehow not entirely 'acceptable'. A mark of such negative attitudes can be that those with the disease feel marginalised, and there may be attempts to keep the illness hidden from all but closest relatives. One example is epilepsy, which in most cases is a short lived and self limiting condition (Jacoby, 1994), and which even in chronic cases, can usually be well controlled by drugs (Keusch et al., 2006). Nevertheless, Kreusch et al. report that in the Netherlands where this condition has been successfully treated for many years, as recently as 1996 a woman was whipped and placed in isolation because it was believed that her seizures resulted from magic.

Some aspects of Parkinson's disease may be stigmatising because they are associated with other more negatively viewed conditions. For example movement disorder can appear as drunkenness, while speech and communication difficulties may be mistakenly associated with mental retardation. The association with ageing can in itself be a cause for stigma (Kahana et al., 2005). As indicated previously, not all PD individuals are elderly, symptoms do not necessarily appear until the disease is well underway, and if diagnosis is early enough many symptoms can be controlled for years. But if there are negative public attitudes to the disease, and stereotypes associated with it that relate it to loss of bodily and cognitive control and rapid deterioration, these stereotypes will also affect those who are diagnosed. They may trigger depression and social withdrawal, both in sufferers and carers. They may delay the seeking of treatment (and thus helpful early intervention) among those with symptoms (Keusch et al., 2006; Link \& Phelan, 2006).

There are few studies about public attitudes to $\mathrm{PD}$ and none in Australia. Greater understanding of popular beliefs about this disease will enable more informed public education campaigns about the nature of Parkinson's. Information on beliefs and attitudes will have the potential to assist in the development of interventions that are aimed to improve lifestyle and coping strategies of those living with the illness. In turn, through such campaigns and interventions it may be possible to reduce perceived stigma associated with Parkinson's and provide more support for sufferers and carers.

The aim of the current study was to ascertain beliefs and attitudes about Parkinson's disease, specifically the extent of negative attitudes, stereotyping and stigma associated with the disease. In addition, a range of factors that might predict negative attitudes were explored. These included demographic variables of age, gender, education and income, as well as variables such as familiarity with and knowledge of the disease, and beliefs about disease seriousness, prevalence, personal likelihood of contracting PD and treatment. At least one previous study has indicated that individuals who perceive they are at risk of contracting a disease are less likely to stereotype others with the disease (Moore \& Rosenthal, 1996). Additionally, less negative attitudes and lower levels of stigma are found amongst those who are more familiar with a disease, either through knowing someone who has it, or being more generally informed (e.g., Shapiro, 2005; Werner, 2005).

\section{Method}

A survey was developed to assess public attitudes and beliefs about PD. Questions were designed to be presented on the telephone, and all but one were 'closed answer' questions in which respondents were read a statement and asked to choose which of several presented options best represented their belief or attitude. Only those who were 18 years or older and had 'heard of' PD were invited to participate. It was expected that in a survey of 200 householders that some may actually have PD, and although they were not the focus of this study, they were nevertheless included as respondents of interest. However, those with PD were presented with a slightly different set of questions that acknowledged their illness. For example, they were not asked 'How worried are you about getting this illness' or 'Over the course of a lifetime, how likely do you think you are to get this illness', as these items were considered inappropriate for someone who already had PD.

The survey contained single items to assess knowledge of a sufferer, perceived commonness of PD, perceived personal likelihood of contracting PD, perceived seriousness of the illness, worry about contracting it, perceived unpleasantness of PD in relation to other diseases, perceived control over symptoms of the disease, beliefs about possible protective measures (against contracting PD), and beliefs about whether it is stigmatised. Respondents were also asked to indicate who they would tell (or who they had told) if they contracted PD, as a further indicator of perceived stigma or discrimination. For each item, four response categories were given forming a Likert-type scale. For example, for the item 'Do you think the symptoms of PD can be controlled by treatment?', the response categories were $0=$ not at all, 1 = some control is possible, 2 = quite a lot of control is possible, and $3=$ The symptoms can be completely controlled with treatment. Additionally, there were two yes/no items concerning belief about whether the illness can be cured, and belief about whether PD occurs more frequently among particular groups in the population (and if so, which groups). This latter item was used as an indicator of whether people with PD were stereotyped. The items were based on a previous study of disease stigma and stereotyping (Moore \& Rosenthal, 1996; Rosenthal \& Moore, 1994). 
Knowledge of PD was assessed through a 13-item true-false measure containing statements about PD, for example 'Parkinson's disease is more common in the elderly' (true) and 'There is a blood test which can be used to diagnose PD' (false). Items were summed to produce a knowledge score. Table 1 shows all items with their answers, which were sourced from the Parkinson's Victoria (www.parkinsons-vic.org.au/) and Parkinson's Australia (www.parkinsons.org.au/) websites.

Attitudes were measured through a 15-item measure, in which survey participants were asked to rate on a 4point scale (from $1=$ 'not at all' to $4=$ 'a great deal') the extent to which they would be worried about a range of potential effects and consequences of $\mathrm{PD}$, such as pain, their relationships, and cost of medical treatment. Items were summed to produce an attitudes score, in which high scores represent more worry about (that is, more negative attitudes towards) PD. The maximum possible score on this scale is 60 (extremely negative attitudes) and the minimum possible score is 15. The attitudes scale had a Cronbach alpha reliability of .85. Table 2 shows all the items.

Demographic items assessed included gender, age group (18-30 years; 31-49 years; 50 and over), education (four categories) and income (6 categories). Data from the survey were analysed using SPSS version 12.1

The project was approved to proceed by the Swinburne University Faculty of Life and Social Sciences Human Ethics Committee. Using the services of the Swinburne Computer-Assisted Telephone Information (CATI) Centre, 200 respondents were surveyed, representing a response rate of approximately $25 \%$ of telephones answered. The survey took on average about 10 minutes to complete, with the telephone operator reading out each question and the response alternatives, then entering the coded response directly into a data base in which respondents were identified only by a code number, that is, responses were anonymous.

Attempts were made to sample equal numbers of males and females across each group within a particular time/cost framework. This proved difficult and the sample, is somewhat under representative of males $(N=$ 74; females $N=126$ ), and younger persons (18-30 years: $N=43$; 31-49 years, $N=80 ; 50$ years and over, $N=77)$. Of the sample surveyed, 4 individuals (2\%) reported that they had Parkinson's disease. The education level of the sample spread across the spectrum, with $22 \%$ having attempted or completed Year 10 (or below) as their highest qualification, 20\% attempted or completed Year 11 or 12 or equivalent, $17 \%$ attempted or completed vocational training, trade certificate or diploma, and $41 \%$ attempted some university education or equivalent. With respect to income, 30\% reported an income of less than $\$ 20,000$,
$37.5 \%$ had incomes between $\$ 20,000$ and $\$ 49,999$, and $22 \%$ had incomes above \$50,000 (4.5\% didn't know their income and $6 \%$ refused this question).

\section{Results}

Note that percentages reported do not always add to exactly $100 \%$ as not all respondents answered all questions. When there were a large number of 'don't knows' or non-respondents (greater than 5\%), this has been reported specifically.

\section{Knowledge and Beliefs about PD}

Commonness Most people thought that PD was 'somewhat common' (62.5\%), with a further $26 \%$ believing it was 'somewhat or extremely rare'. Ten percent thought it was very or extremely common. Estimates of true prevalence could be described as 'somewhat common', and vary from 1 to 2 persons per 1000 in the population, this rate rising considerably for the 65 years and over group, where the rate is more like one in every 100 persons (Parkinson's Australia website, http://www.parkinsons.org.au/).

Likelihood Most people thought they were somewhat unlikely (48\%) or extremely unlikely (26\%) to ever contract PD, with $12.5 \%$ believing they were somewhat likely and a small $2.5 \%$ very or extremely likely. 'Don't knows' comprised 9\%. Those with PD ( $N$ $=4$ ) were not presented with this item.

Not surprisingly given this low expectation of contracting the illness, most people were not at all worried about getting it (51\%) or not very worried (25\%). A few were somewhat worried (14.5\%), very worried (4\%) or extremely worried (2\%).

Seriousness/unpleasantness The majority of respondents saw $\mathrm{PD}$ as very serious (63\%), or extremely serious (22.5\%). The rest saw it as somewhat serious (12\%) or not very serious (1.5\%). Correspondingly, $10 \%$ thought it would be the worst disease they could imagine happening to them, 52.5\% viewed it as extremely unpleasant but not the worst they could imagine, $27.5 \%$ as very unpleasant and $13 \%$ as unpleasant but bearable.

Treatment/cure Most people (74\%) were aware that there is no cure for Parkinson's; 15\% thought there was and $11 \%$ were not sure. Similarly, most people were aware that there was nothing or very little they could do to protect themselves from the disease (52.5\%), although some thought there were a few things they could do (16.5\%), or a lot they could do (8\%). A substantial minority (21\%) said they didn't know. When asked about treatment, most (70\%) agreed that some disease control is possible with treatment, $20 \%$ thought quite of lot of control was possible and 2\% believed that the symptoms of Parkinson's could be completely controlled by treatment (5.5\% didn't know, and $2.5 \%$ thought treatment was completely ineffective). 
Knowledge/information about PD Over half the sample (55\%) did not know anyone with PD, but $16.5 \%$ knew an acquaintance or acquaintances with the illness, and $26.5 \%$ knew at least one close friend or family member. Four people in the sample $(2 \%)$ had PD themselves.

Table 1 shows percent correct answers on the knowledge items. The mean score for the sample was 8.6 (out of 13, representing an average of $66 \%$ of items correct), with a standard deviation of 1.9 and a range of 2 to 13 items correct. Virtually everyone realised that PD is not a form of insanity and that it is not contagious. Most knew that drugs help the symptoms; people with $\mathrm{PD}$ are often still able to work; it most commonly afflicts the elderly; major symptoms are tremor and joint stiffness; depression is a common consequence of the disease. There was a widespread incorrect belief that a blood test can be used to diagnose $\mathrm{PD}$, and that it significantly shortens the lifespan. Only about half the sample knew that the causes of PD are unknown, exercise helps, the disease progresses slowly, and dementia is not inevitable.

Table 1: Results of knowledge test about Parkinson's disease.

\begin{tabular}{|c|c|c|}
\hline Item & $\begin{array}{c}\% \\
\text { correct } \\
\end{array}$ & Answer \\
\hline $\begin{array}{l}\text { 1. Parkinson's disease is more } \\
\text { common in the elderly? }\end{array}$ & 70.0 & $\mathrm{~T}$ \\
\hline $\begin{array}{l}\text { 2. There is a blood test which can } \\
\text { be used to diagnose Parkinson's? }\end{array}$ & 26.0 & $\mathrm{~F}$ \\
\hline $\begin{array}{l}\text { 3. Parkinson's disease } \\
\text { significantly shortens the lifespan? }\end{array}$ & 35.0 & $\mathrm{~F}$ \\
\hline $\begin{array}{l}\text { 4. The causes of Parkinson's } \\
\text { disease are unknown }\end{array}$ & 53.5 & $\mathrm{~T}$ \\
\hline $\begin{array}{l}\text { 5. The symptoms of Parkinson's } \\
\text { disease can be improved through } \\
\text { exercise }\end{array}$ & 57.5 & $\mathrm{~T}$ \\
\hline $\begin{array}{l}\text { 6. Treatment with drugs can } \\
\text { improve the symptoms of } \\
\text { Parkinson's }\end{array}$ & 85.5 & $\mathrm{~T}$ \\
\hline $\begin{array}{l}\text { 7. Parkinson's disease progresses } \\
\text { very rapidly }\end{array}$ & 54.0 & $\mathrm{~F}$ \\
\hline $\begin{array}{l}\text { 8. Dementia is an inevitable } \\
\text { outcome of Parkinson's }\end{array}$ & 53.0 & $\mathrm{~F}$ \\
\hline $\begin{array}{l}\text { 9. Depression is common among } \\
\text { those with Parkinson's }\end{array}$ & 79.0 & $\mathrm{~T}$ \\
\hline $\begin{array}{l}\text { 10. Tremor and muscle stiffness } \\
\text { are the main symptoms of } \\
\text { Parkinson's }\end{array}$ & 76.5 & $\mathrm{~T}$ \\
\hline $\begin{array}{l}\text { 11. Parkinson's disease is a form } \\
\text { of insanity }\end{array}$ & 91.5 & $\mathrm{~F}$ \\
\hline $\begin{array}{l}\text { 12. Parkinson's disease is } \\
\text { contagious }\end{array}$ & 99.0 & F \\
\hline $\begin{array}{l}\text { 13. You can't work if you have } \\
\text { Parkinson's disease }\end{array}$ & 79.0 & $\mathrm{~F}$ \\
\hline
\end{tabular}

People who knew someone with PD ( $m=9.2)$ were significantly more knowledgeable than those who did not know anyone with the disease $(m=8.1)$. Not surprisingly, those who actually had the disease ( $m=$ $10.3)$ were more knowledgeable than other groups $(F(3$, $196)=6.62, p<.001)$. There were no significant gender, age, education or income group differences in knowledge.

\section{Stigma and Stereotype}

When asked "Do you think there is a stigma associated with Parkinson's disease?" 47\% thought there was (8.5\% very much so; $23 \%$ somewhat; $15.5 \%$ a little) while $46 \%$ thought there was 'no stigma at all'. Seven percent were unsure. There were no age, gender, education or income level differences in stigma beliefs. Interestingly, significant postcode area differences indicated that there was more stigma attached to Parkinson's from among those living in outer suburban/rural areas (postcodes 3200 and above) than from those in inner city and suburban areas (postcodes 3199 and below) $(F(3,196)=3.88, p<.01)$.

Nearly half (46.5\%) believed that the disease occurs more frequently among particular groups in the population (33\% said no to this question and 20.5\% were unsure). Groups nominated as more likely to suffer from PD demonstrated that the sample were engaging in relatively accurate and non-negative stereotyping. Most frequently mentioned were the aged ( $N=69$ nominations), males $(N=12)$ and elderly males $(N=9)$. The following groups were nominated by between one and three people: middle aged people, nervous people, coffee drinkers, smokers, people who drink and smoke, people with neurological problems, those with a genetic predisposition and boxers. Stereotyping was not related to gender, income or postcode. Younger people were more likely to stereotype a PD sufferer than older people $\chi^{2}(2)=$ 17.61, $p<.001)$. A significant relationship with education (with higher educated individuals engaging in more stereotyping) disappeared when age was controlled for, as in this sample, younger individuals had higher levels of education. Stereotyping and perceived stigma were not related.

Keeping an illness hidden from others can be a reflection of perceived stigma associated with the illness. Regarding who they would tell if they contracted PD, there was a wide spread of responses, with $30.5 \%$ saying they would tell anyone they thought was interested. Eleven percent would tell family, friends and work colleagues, 33\% would tell family and close friends only, $19.5 \%$ would tell immediate family and $2.5 \%$ would tell no-one. Thus more than half the sample restricted the number of people they would tell. The number of people that participants would tell if they had PD was unrelated to gender, age, income, education, postcode, perceived stigma or stereotyping beliefs. However, those who restricted the range of people they would tell had less knowledge of the 
disease than non-restrictors (knowledge score of nonrestrictors $m=9.23$, restrictors $m=8.26 ; F(1,194)=$ $11.08, p<.01)$.

\section{Attitudes Toward PD}

Table 2 shows the percent of individuals who would be 'not worried', 'somewhat worried' or 'greatly worried' about 15 different aspects of PD if they had the illness. The mean negative attitudes score of the sample was 42.7 ( $s d=9.1$, possible range 15-60).

Table 2: Percent of respondents who would worry about potential consequences of Parkinson's disease.

\begin{tabular}{|c|c|c|c|}
\hline Item & $\begin{array}{c}\% \text { not } \\
\text { worried }\end{array}$ & $\begin{array}{c}\% \\
\text { somewhat } \\
\text { worried }\end{array}$ & $\begin{array}{c}\text { \% } \\
\text { greatly } \\
\text { worried }\end{array}$ \\
\hline Pain & 34.5 & 36 & 28.5 \\
\hline $\begin{array}{l}\text { Physical } \\
\text { disability }\end{array}$ & 19.5 & 27 & 53 \\
\hline $\begin{array}{l}\text { Mental } \\
\text { deterioration }\end{array}$ & 18 & 21.5 & 59.5 \\
\hline $\begin{array}{l}\text { Being dependent } \\
\text { on others }\end{array}$ & 14.5 & 26.5 & 58.5 \\
\hline $\begin{array}{l}\text { What people } \\
\text { think }\end{array}$ & 68 & 19.5 & 11.5 \\
\hline $\begin{array}{l}\text { Your } \\
\text { relationships }\end{array}$ & 42 & 27 & 29.5 \\
\hline $\begin{array}{l}\text { Who would look } \\
\text { after you }\end{array}$ & 42.5 & 25.5 & 30.5 \\
\hline $\begin{array}{l}\text { How you would } \\
\text { support self/ your } \\
\text { family }\end{array}$ & 32 & 19 & 47.5 \\
\hline $\begin{array}{l}\text { Costs of medical } \\
\text { treatment }\end{array}$ & 29.5 & 29 & 40.5 \\
\hline $\begin{array}{l}\text { Losing } \\
\text { friendships }\end{array}$ & 50 & 19.5 & 30 \\
\hline Being a burden & 18 & 22 & 61 \\
\hline $\begin{array}{l}\text { Not being able to } \\
\text { socialise as much }\end{array}$ & 29.5 & 27.5 & 41.5 \\
\hline $\begin{array}{l}\text { Being lonely or } \\
\text { alone }\end{array}$ & 45 & 25.5 & 28 \\
\hline Sexuality & 54 & 25 & 17.5 \\
\hline $\begin{array}{l}\text { Finding the best } \\
\text { treatment }\end{array}$ & 24 & 29 & 46 \\
\hline
\end{tabular}

Note. Percentages do not always add to exactly $100 \%$ due to rounding and/or missing data.

The potential consequence of PD most concerning to people was being a burden, followed by mental deterioration and being dependent on others. Less worrisome were social issues such as what people think, sexuality, losing friendships, or being lonely/alone.

People with negative attitudes to PD were more likely to view the illness as stigmatised $(r=.17, p<$ $.05)$, however attitudes were unrelated to stereotyping. Specific attitudinal items relating to stigma were worries about being a burden $(r=.23, p<.05)$ and what people would think of them if they contracted Parkinson's $(r=.22, p<.05)$. Negative attitudes were also related to perceived unpleasantness of the disease $(r=.20, p<.01)$. Age was also associated, with people aged 50 years and over having significantly more positive attitudes $(m=39.9)$ than those in the 31-49 years age group $(m=43.1)$ or the 18 -30 years age group $(m=46.2)(F(2,178)=5.78, p<.01)$. There were no significant gender, income or postcode differences in attitudes. Those with higher levels of education had more negative attitudes to $\mathrm{PD}$, but this relationship disappeared when controlling for age (as with the relationship between stereotyping and education).

Those with more negative attitudes to PD were less likely to know someone with the disease $(r=-.22, p<$ $.01)$. Additionally, negative attitudes were associated with lower scores on the scale measuring knowledge about Parkinson's $(r=-.16, p<.05)$. Two items in the knowledge scale were individually related to attitudes score. People who (incorrectly) thought that Parkinson's disease significantly shortened the lifespan, or that the disease progresses very rapidly, had more negative attitudes to the disease $(r=-.19, p<.05 ; r=$ $.22, p<.01$, respectively).

\section{Predicting Attitudes to PD}

The significant correlates of negative attitudes to PD (as indicated above) were stigma beliefs, unpleasantness beliefs, age, knowledge of a sufferer and knowledge of the disease. Using a standard regression with these correlates as independent variables, negative attitudes to PD were significantly predicted $(F(5,168)=5.69, p<.001)$, with (younger) age, belief in the relative unpleasantness of the disease in relation to other diseases, and belief that the disease is stigmatised as significant independent predictors (betas $=-.19, .17, .18$ respectively, all $p<.05)$. The percent of variance accounted for by the regression equation was a relatively low 14.5 percent.

\section{Discussion}

There is a good public understanding that Parkinson's disease is a relatively common and generally serious disease. However, as with negative events in general, most people do not consider themselves likely to be susceptible. Additionally, preventative health interventions are not particularly relevant to this disease, and the majority realise that there is little or nothing they can do to protect themselves from it, given our current levels of medical knowledge and understanding. Thus, unless the disease is personalised in some way, for example by knowing someone who has it, it is unlikely to impinge very much on public consciousness.

However, of concern is that nearly half the respondents saw a stigma attached to this disease. The nature of this stigma was unclear, as the stereotypes associated with Parkinson's were by and large not in 
themselves negative (older people and males). Nevertheless, a small number of people related the disease to lifestyle factors such as drinking too much coffee or smoking and, as discussed previously, there can be social prejudice against ageing itself. Those who believed there was a stigma had, not surprisingly, more negative attitudes to Parkinson's. Specifically they were worried about being a burden and what people would think of them if they contracted the disease. However they did not differ from the non-stigmatisers, in terms of beliefs about disease seriousness, whether it was contagious, or associated with depression, mental deterioration or insanity. Nor were there gender or age differences with respect to stigma beliefs. So we are left with the question as to the nature and source of this stigma, and what sorts of interventions might overcome it. That such a stigma exists and is so widespread must ultimately make life more difficult for those with the disease and their carers. It is likely to be associated with poorer levels of informal social support, community support, as well as fewer work and leisure opportunities for those living with PD. Stigma can lead to discrimination - subtle and overt - which may be associated with depression and poorer adjustment among those with the stigmatised condition. That stigma was higher in areas outside the inner city could compound problems for those with PD in rural and outer suburban areas, as in these areas there are also likely to be fewer organisational and medical supports available.

Knowledge of Parkinson's disease was quite good, but there were a few widespread misconceptions. It was commonly believed that PD could be diagnosed with a blood test. A significant percent believed that the disease progresses rapidly, and inevitably leads to dementia and a shortened lifespan. These beliefs do not acknowledge the more common course of this illness, in which diagnosis may be slow in coming (especially for younger sufferers who do not fit the 'profile'), and the sufferer may live with the disease for many years, with quite gradual loss of function. Such a disease course may mean that the person with PD is able to work for some years, and changes to social and recreational life need occur only gradually. To ensure that these years living with the disease are as fulfilling as they can possibly be, those with PD need the kind of social and community support that is long-term and that does not write them off as 'too ill' to be involved. Public education on the 'can do' aspects of those with PD may be of value here.

Worries about possible effects of PD were mostly about being a burden, dependent on others, mental deterioration and physical disability. These negative attitudes were more common in younger age groups and among those who knew less about PD, both in terms of general knowledge and knowing someone with the disease. Greater public knowledge about Parkinson's would help in demystifying the disease. For example, understanding that there are ways to manage disease symptoms, especially in the early stages, would reduce fear of the disease, lessen the impact on those diagnosed (and their families), and possibly reduce stigma.

As with the data on knowledge, the attitude data suggest a need for public education which stresses the extent that those with PD, especially in the early stages, can still lead productive and fulfilling lives. This may be of particular importance for those approximately 15 percent of sufferers who experience symptoms at relatively young ages, such as prior to 50 years. These individuals are likely to have greater difficulty coming to terms with the disease because of negative public attitudes toward it (including, often, their own negative attitudes), and because they fall outside the stereotype of the older sufferer. Special programs for early onset PD sufferers are indicated, in which there can be support and assistance toward developing lifestyle strategies that maximise positive psychosocial outcomes.

\section{Acknowledgments}

This study was financially supported by Swinburne Alumni and Parkinson's Victoria, to whom thanks are due. Thanks also to Allison Clarke for her excellent research assistance and to the efficient and cheerful staff of the Swinburne CATI Centre.

\section{References}

Abudi, S., Bar-Tal, Y., Ziv, L., \& Fish, M. (1997). Parkinson's disease symptoms - patients' perceptions. Journal of Advanced Nursing, 25, 54-59.

Anderson, K. N., Anderson, L. E., \& Glanze, W. (1998). Mosby's medical, nursing, \& allied health dictionary. (5th ed.). Missouri: Mosby-Year Book, Inc.

Clarke, J. (2005). Portrayal of childhood cancer in English language magazines in North America: 19702001. Journal of Health Communication, 10(7), 593607.

Hills, M. D., \& MacKenzie, H. C. (2002). New Zealand community attitudes toward people with epilepsy. Epilepsia, 43(12), 1583-1589.

Jacoby, A. (1994). Felt versus enacted stigma: A concept revisited. Social Science and Medicine, 38(2), 269-274.

Jenerette, C., Funk, M., \& Murdaugh, C. (2005). Sickle cell disease: A stigmatizing condition that may lead to depression. Issues in Mental Health Nursing, 26(10), 1081-1101.

Keusch, G. T., Wilentz, J., \& Kleinman, A. (2006). Stigma and global health: Developing a research agenda. Lancet, 367, 525-527.

Kahana, E,.King, C.,Kahana, B., Menne, H.,Webster, N. J., Dan, A., Kercher, K.,Bohne, A., \& Lechner, C. (2005). Successful aging in the face of chronic disease. In Wykle, M. L., Whitehouse, P. J. \& Morris, D. L. (Eds). Successful aging through the 
life span: Intergenerational issues in health. New York, NY, US: Springer Publishing Co, pp. 101-126.

Link, B. G., \& Phelan, J. C. (2006). Stigma and its public health implications. Lancet, 367, 528-529.

Lyons, K. D., \& Tickle-Degnen, L. (2003). Dramaturgical challenges of Parkinson's disease. OTJR, 23, 27-35.

Mateu-Gelabert, P., Maslow, C., \& Flom, P. L. (2005). Keeping it together: Stigma, response, and perception of risk in relationships between drug injectors and crack smokers, and other community residents. AIDS Care, 17(7), 802-813.

Moore, S., \& Rosenthal, D. (1996). Young people assess their risk of sexually transmissible diseases. Psychology and Health, 11, 345-355.

Parkinson's Victoria Inc (2005, October). Parkinson's profile. Retrieved $13^{\text {th }}$ October, 2005, from http://www.parkinsons-vic.org.au/

Reidpath, D. D., Brijnath, B., \& Chan, K. Y. (2005). An Asia Pacific six-country study on HIV-related discrimination: Introduction. AIDS Care, 17(Suppl2), S117-S127.

Rosenthal, D., \& Moore, S. (1994). Stigma and ignorance: Young people's beliefs about STDs. Venereology, 7, 62-66.

Schrag, A., Jahanshahi, M., \& Quinn, N. P. (2001). What contributes to depression in Parkinson's disease? Psychological Medicine, 31(1), 65-73.

Schreurs, K. M. G., De Ridder, D. T. D., \& Bensing, J. M. (2000). A one year study of coping, social support and quality of life on Parkinson's disease. Psychology \& Health, 15, 109.

Shapiro, P.D. (2005). How close is too close?: The negative relationship between knowledge of HIV transmission routes and social distancing tendencies. Social Science Journal, 42(4), 629-637.

Simons, G., Pasqualini, M. C. S., Reddy, V., \& Wood, J. (2004). Emotional and nonemotional facial expressions in people with Parkinson's disease. Journal of the International Neuropsychological Society, 10, 521-535.

Werner, P. (2005). Social distance towards a person with Alzheimer's disease. International Journal of Geriatric Psychiatry, 20, 182-188.

Correspondence to: Professor Susan M Moore

Faculty of Life and Social Sciences

Swinburne University of Technology

PO Box 218, Hawthorn, Vic, 3122

smoore@swin.edu.au

\section{Research Profile}

Professor Susan Moore is a developmental/social psychologist who has worked in Victorian Universities for over thirty years. Her research interests include adolescent development, particularly sexuality and risktaking behaviour, gambling and health promotion. In recent years she has been investigating the impact of chronic illness conditions on individuals and their families. Professor Moore has had more than 100 articles published and several books. She is currently working on a project to evaluate the effect of a lifestyle intervention on the prevention of Type 2 diabetes.

Dr. Simon Knowles is a lecturer in Psychology, Faculty of Life and Social Sciences, Swinburne University of Technology. Research interests include investigating the impact of work lifestyle (specifically shiftwork) and the mediating role of stress and various coping strategies on individual psychological and physiological well-being. 